\title{
Cromatografia líquida com fase quiral aplicada na separação enantiomérica de fármacos cardiovasculares
}

\author{
Anil Kumar Singh, Érika Rosa Maria Kedor-Hackmann, Maria Inês Rocha Miritello Santoro* \\ Departamento de Farmácia, Faculdade de Ciências Farmacêuticas, Universidade de São Paulo
}

*Correspondência:

M. I. R. M. Santoro

Departamento de Farmácia

Faculdade de Ciências Farmacêuticas

Universidade de São Paulo

Caixa Postal 66083

05315-970 - São Paulo, Brasil

E-mail: ines@usp.br
A maioria dos agentes terapêuticos, freqüentemente prescritos, é formulada e comercializada sob a forma racêmica, embora, para alguns deles, já tenha sido demonstrado que os efeitos farmacológicos elou tóxicos estejam relacionados apenas a um dos enantiômeros. Além disso, é conhecido o fato de que os enantiômeros podem apresentar perfis farmacocinéticos e farmacodinâmicos diferentes. Neste trabalho foram selecionados compostos que fazem parte de um importante grupo de fármacos muito empregados na terapêutica. São fármacos freqüentemente prescritos em doenças cardiovasculares. As separações enantioméricas diretas do atenolol, betaxolol, metoprolol e nadolol foram obtidas utilizando-se fase estacionária quiral do tipo carbamato de celulose tris-3,5-dimetilfenil, Chiralcel $O D^{\circledR},(250 x$ $4.6 \mathrm{~mm}, 10 \mu \mathrm{m})$. Os enantiômeros do pindolol foram separados com fase estacionária quiral derivada de dinitrobenzoil (DNB), aBurke $2^{\circledR},(250 \times 4.6 \mathrm{~mm}, 10 \mu \mathrm{m})$. Os fármacos foram cromatografados à temperatura ambiente, com volume de injeção de $20 \mu \mathrm{L}$. A detecção foi efetuada em $276 \mathrm{~nm}$ exceto para o pindolol, que foi detectado em $220 \mathrm{~nm}$. Os métodos propostos neste trabalho empregando CLAE-FEQs oferecem vantagens sobre as técnicas clássicas de separação de enantiômeros e podem ser empregados na análise quantitativa dos enantiômeros em preparações farmacêuticas e amostras biológicas.

\section{Unitermos}

- Cromatografia líquida

- Fase estacionária quiral

- Separação enantiomérica

- $\beta$-Bloqueadores

\section{INTRODUÇÃO}

A quiralidade dos compostos químicos, especialmente de compostos terapêuticos, é tema muito importante do ponto de vista farmacológico, farmacocinético, toxicológico e nos órgãos fiscais de controle de qualidade de medicamentos. Para garantir a segurança e a eficiência dos fármacos disponíveis e em desenvolvimento, é necessário isolar e examinar cada um dos enantiômeros separadamente. Além disso, é importante, também, o controle da composição estereoquímica desde a síntese até o consumo, envolvendo estudos farmacológicos, fabricação e controle de qualidade (Santoro, Singh, 2001).

A separação cromatográfica de enantiômeros pode ser alcançada por vários métodos, todavia, é sempre necessário o uso de algum tipo de discriminador ou seletor quiral (Dappen, Arm, Mayer, 1986; Wainer, 1993). Entre os métodos analíticos mais empregados para a separação, 
identificação e quantificação de enantiômeros está a cromatografia líquida de alta eficiência com fase estacionária quiral (CLAE-FEQ) (Ahuja, 1991). A técnica tem sido amplamente aplicada na determinação da pureza óptica e da constituição estereoisomérica de medicamentos, matérias-primas, preparações farmacêuticas e fluídos biológicos e em estudos de instabilidade configuracional de fármacos (racemização, enantiomerização, epimerização) e determinação da farmacocinética e metabolismo de fármacos (Wainer, 1993).

Os enantiômeros podem ser resolvidos pela formação de complexos diastereoisoméricos entre o soluto e as moléculas quirais, as quais estão ligadas à sílica. Neste trabalho, foram empregadas duas destas fases para separar, de forma rápida e eficiente, os enantiômeros de $\beta$ bloqueadores como atenolol, betaxolol, metoprolol, nadolol e pindolol. A fase estacionária é conhecida como fase estacionária quiral (FEQs) e seu uso tem crescido rapidamente na área da separação quiral.

Os $\beta$-bloquedores representam o grupo de fármacos dos mais importantes e mais prescritos devido ao fato de que as doenças cardiovasculares estão entre as maiores causas de mortalidade mundial (Belas et al., 1995; Egginger et al., 1993). Atenolol, betaxolol, metoprolol, nadolol e pindolol são agentes bloqueadores de receptores $\beta$-adrenérgicos empregados principalmente, na angina pectoris, hipertensão, certas arritmias cardíacas e no tratamento do glaucoma (Darmon, Thenot, 1986; Foye, 1989; Hoffman, Lefkowitz, 1996; Krstulovic et al., 1988; Mehvar, Brocks, 2001; Srinivas et al., 1996; Zhang, Stewart, Ujhelyi, 1995).

Os agentes bloqueadores $\beta$-adrenérgicos são derivados de ariletanolaminas e de ariloxipropanolaminas com valores de pKa entre 9,0 e 10,0 (Moffat et al., 1986). Suas

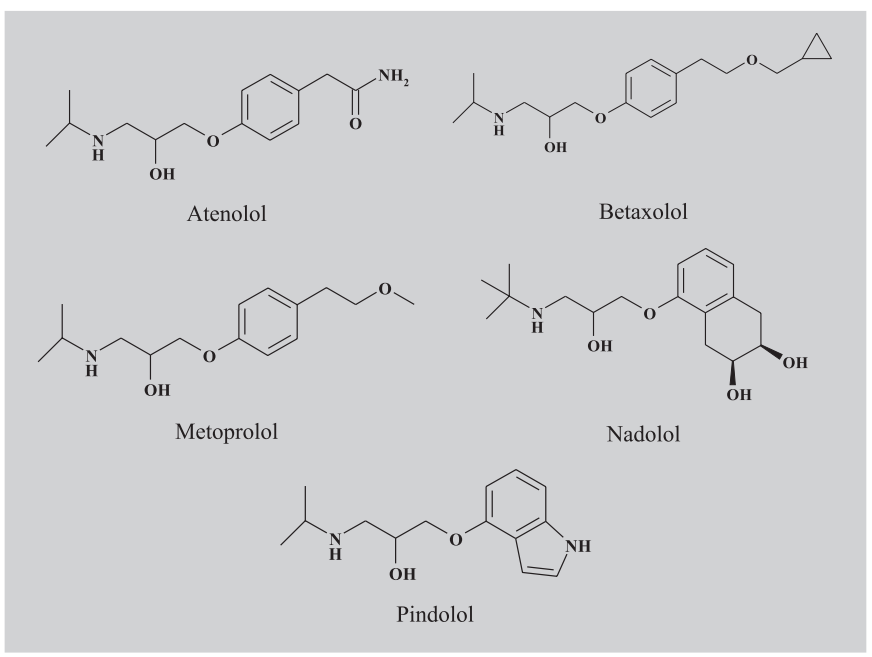

FIGURA 1 - Estrutura química dos $\beta$-bloqueadores. estruturas químicas podem ser vistas na Figura 1, onde pelo menos um centro quiral está presente na porção $\alpha$ hidroxietilamina (aminoálcool). Faz exceção o nadolol, que possui três centros quirais (Belas et al., 1995; Mehvar, Brocks, 2001; Srinivas et al., 1996; Aboul-Enein, AbouBasha, 1996). A maioria dos agentes $\beta$-bloqueadores freqüentemente prescritos é formulada e comercializada na forma racêmica, embora, para alguns deles, já tenha sido demonstrado que o enantiômero (S)- é o responsável pelo efeito farmacológico principal (Mehvar, Brocks, 2001).

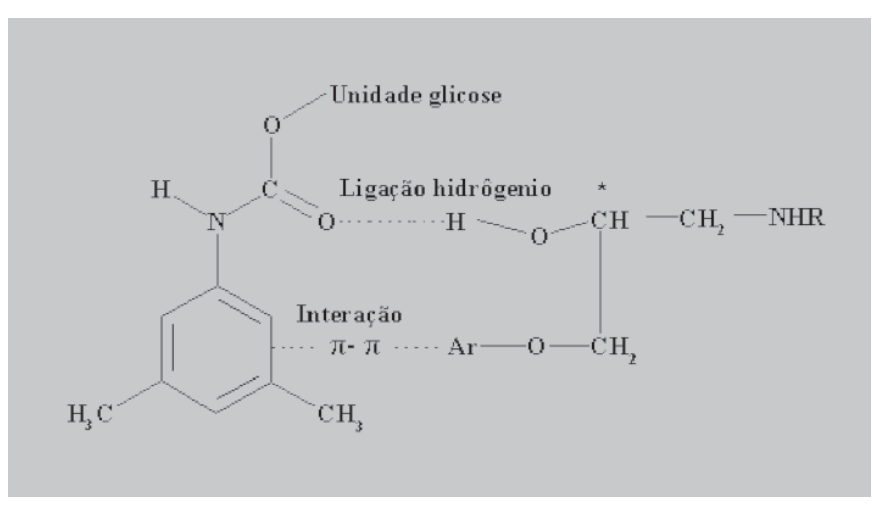

FIGURA 2 - Interação entre a fase estacionária quiral da coluna Chiralcel $\mathrm{OD}^{\circledR}$ e os $\beta$-bloqueadores (Aboul-Enein 1993).

No Brasil, os agentes $\beta$-bloqueadores são comercializados em diversas formas farmacêuticas, tais como soluções injetáveis, soluções oftálmicas e comprimidos (DEF 2003). O objetivo principal deste trabalho foi a obtenção das condições ideais para a separação enantiomérica do atenolol, betaxolol, metoprolol, nadolol e pindolol empregando o método de CLAE-FEQ. Para tanto, foram utilizadas duas fases estacionárias quirais uma derivada de celulose (Chiralcel OD $\left.{ }^{\circledR}\right)$ (Figura 2) e a outra derivada de dinitrobenzoila $\left(\alpha\right.$-Burke $\left.2^{\circledR}\right)$ (Figura 3 ).

Recentemente, alguns pesquisadores empregaram cromatografia líquida de alta eficiência com colunas dos tipos Chiralcel OD ${ }^{\circledR}$ (Balmer et al., 1991; Ching et al., 1989; Ekelund et al., 1995; Herring, Bastian, Lalonde, 1991; Krstulovic, 1988; Rutledge, Garrick, 1989; Straka et al., 1990; Zhang, Stewart, Ujhelyi, 1995), $\beta$-ciclodextrina (Ekelund et al., 1995; He et al., 1993; Ward, Armstrong, 1988) e $\alpha$-1-ácido glicoproteína (AGP) (Berthault, Kintz, Mangin, 1997; Ceccato, Hubert, Crommen, 1997; Enquist, Hermansson, 1990; Hermansson, Von Bahr, 1982; Svensson, Vessman, Karlsson, 1999) e antibiótico macrocíclico (teicoplanina - Chirobiotic $\mathrm{T}^{\circledR}$ ) (Lamprecht et al., 2000; Mistry, Leslie, Eddington, 2001) para a determinação enantiomérica dos 
$\beta$-bloqueadores. A maioria dos estudos estereoespecíficos com $\beta$-bloqueadores foi aplicada na determinação enantiomérica em amostras biológicas envolvendo etapas vagarosas de extração.

Os métodos cromatográficos desenvolvidos e padronizados nesta pesquisa podem ser aplicados, após validação, na análise de amostras comerciais contendo $\beta$ bloqueadores, com o objetivo de se avaliar a constituição e a pureza enantiomérica destes fármacos nos medicamentos.

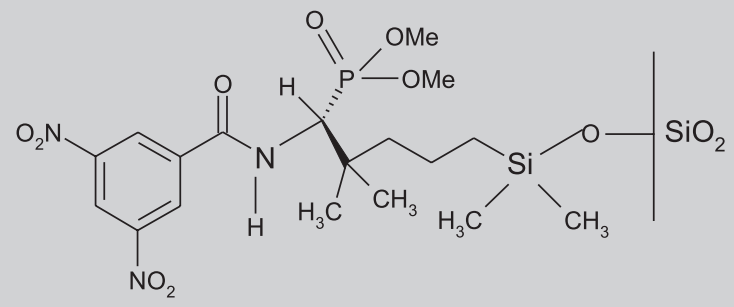

(S, S) $\alpha$-BURKE $2^{\circledR}$

FIGURA 3 - Estrutura da fase estacionária quiral $(\mathrm{S}, \mathrm{S}) \alpha$ Burke $2^{\circledR}$ (CHIRAL Application Guide, 2004; Pirkle, Burke, 1991).

\section{MATERIAL E MÉTODOS}

\section{Reagentes, soluções e solventes}

Hexano, Merck ${ }^{\circledR}$ grau cromatográfico, Isopropanol, OmniSolv ${ }^{\circledR}$ grau cromatográfico, Etanol OmniSolv ${ }^{\circledR}$ grau cromatográfico, Acetonitrila, OmniSolv ${ }^{\circledR}$ grau cromatográfico, Dietilamina, Aldrich ${ }^{\circledR}$ grau analítico, Ácido acético glacial, Merck ${ }^{\circledR}$ grau analítico, Acetato de amônio, Merck $^{\circledR}$ grau analítico,

\section{Fármacos padrão}

(R, S) - Atenolol (99\%), Sigma ${ }^{\circledR}$, St. Louis, MO, USA (R) - Atenolol (99\%), Aldrich ${ }^{\circledR}$, Milwaukee, WI, USA (S) - Atenolol (99\%), Aldrich ${ }^{\circledR}$, Milwaukee, WI, USA (R, S) - Cloridrato de betaxolol (98\%), gentilmente cedido por uma industria farmacêutica e empregado como substancia química de referência sem ulterior purificação

$(\mathrm{R}, \mathrm{S})$ - Tartarato de metoprolol R (+) (98\%), Sigma ${ }^{\circledR}$, St. Louis, MO, USA
(R) - Cloridrato de metoprolol (98\%), cedido pela Astra Zeneca, Suécia

(S) - Cloridrato de metoprolol (98\%), cedido pela Astra Zeneca, Suécia

$(\mathrm{R}, \mathrm{S})$ - Nadolol, Sigma ${ }^{\circledR}$

(R, S) - Pindolol (97\%), Aldrich ${ }^{\circledR}$, Milwaukee, WI, USA

Estes compostos foram adquiridos comercialmente e empregados como substâncias químicas de referência sem prévia purificação e testes analíticos.

\section{Equipamentos}

Além dos equipamentos comumente empregados em laboratórios, foram utilizados os seguintes:

> Espectrofotômetro Beckman DU série 70, acoplado à impressora, com cubeta de $1 \mathrm{~cm}$;

> Sistema de cromatografia líquida de alta eficiência, modelo Varian 5000 (Varian ${ }^{\circledR}$ Associates, CA, USA); Válvula giratória de injeção, modelo 7125 , Rheodyne ${ }^{\circledR}$ com "loop" de $20 \mu \mathrm{L}$; Detector de ultravioleta variável, Varian modelo 4000; Integrador modelo 4400 (Varian Associates, CA, USA);

Fase estacionária quiral: (a) Chiralcel OD ${ }^{\circledR}$ (250 x 4,6 mm d.i) (carbamato de celulose tris-3,5dimetilfenil em partículas de sílica de $10 \mu \mathrm{m}$ (Daicel Chemical Industries, Ltd. Japão); (b) "Brush-Type" (S, S)- $\alpha$-Burke $2^{\circledR}(250 \times 4,6 \mathrm{~mm}$ d.i $)$ (derivada de dimetil$N$-3,5-dinitrobenzoil- $\alpha$-amino-2,2-dimetil-4pentilfosfonato, ligada covalentemente a partículas de sílica-gel esféricas de tamanho $5 \mu \mathrm{m}$, do tipo mercaptopropil, Regis Technologies Inc. Illinois, USA.);

> Ultra-som modelo Thorton T-14,

$>$ Aparelho de filtração a vácuo,

$>$ Membrana de filtro hidrofóbica Millipore ${ }^{\circledR}$ GVHP $0,45 \mu \mathrm{m}$ de tamanho de poro, diâmetro de $47 \mathrm{~mm}$ (Millipore Corporation, MA, USA)

> Unidade filtrante FGLP $0,45 \mu \mathrm{m}$ de tamanho de poro, diâmetro de $13 \mathrm{~mm}$, não-estéril (Millipore Corporation, MA, USA).

\section{MÉTODOS}

\section{Separação dos enantiômeros de $\boldsymbol{\beta}$-bloqueadores}

As condições analíticas para a separação dos enantiômeros dos $\beta$-bloqueadores foram padronizadas através do sistema de cromatografia líquida de alta eficiência, usando coluna do tipo Chiralcel $\mathrm{OD}^{\circledR}$ ou do tipo $\alpha$-Burke $2^{\circledR}$, como fase estacionária quiral. As amostras fo- 


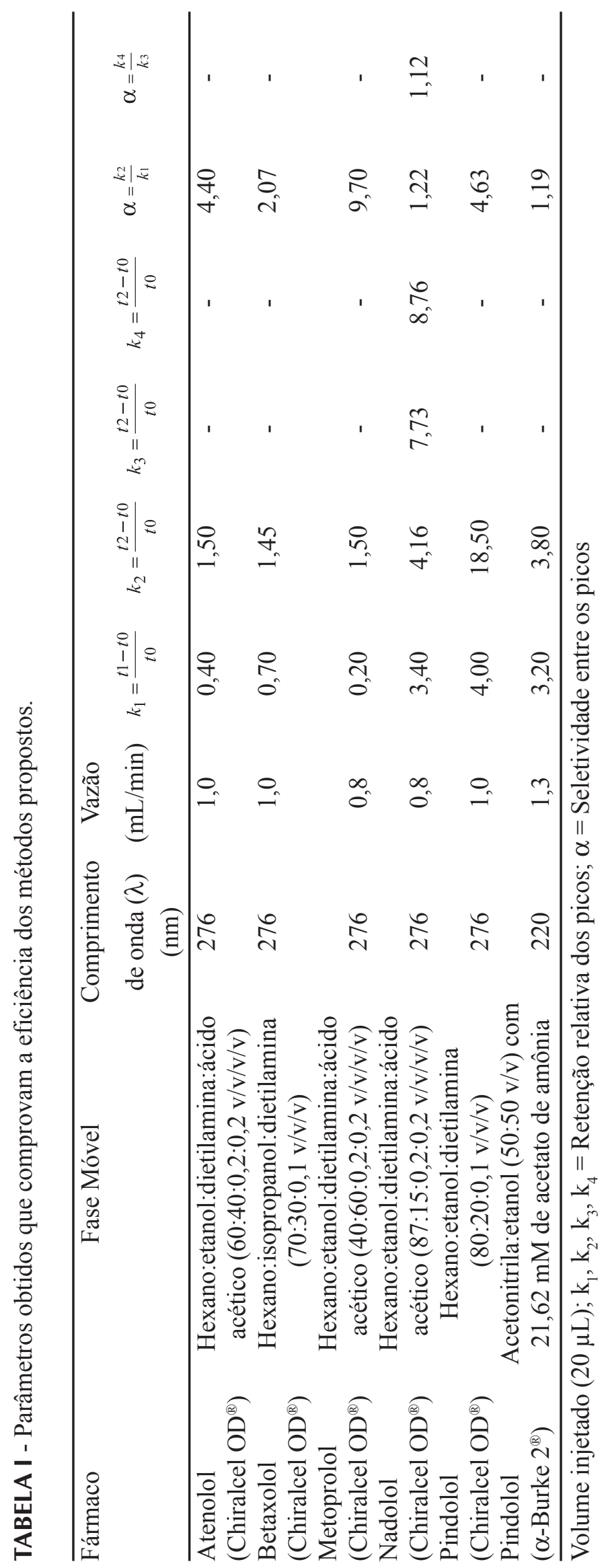



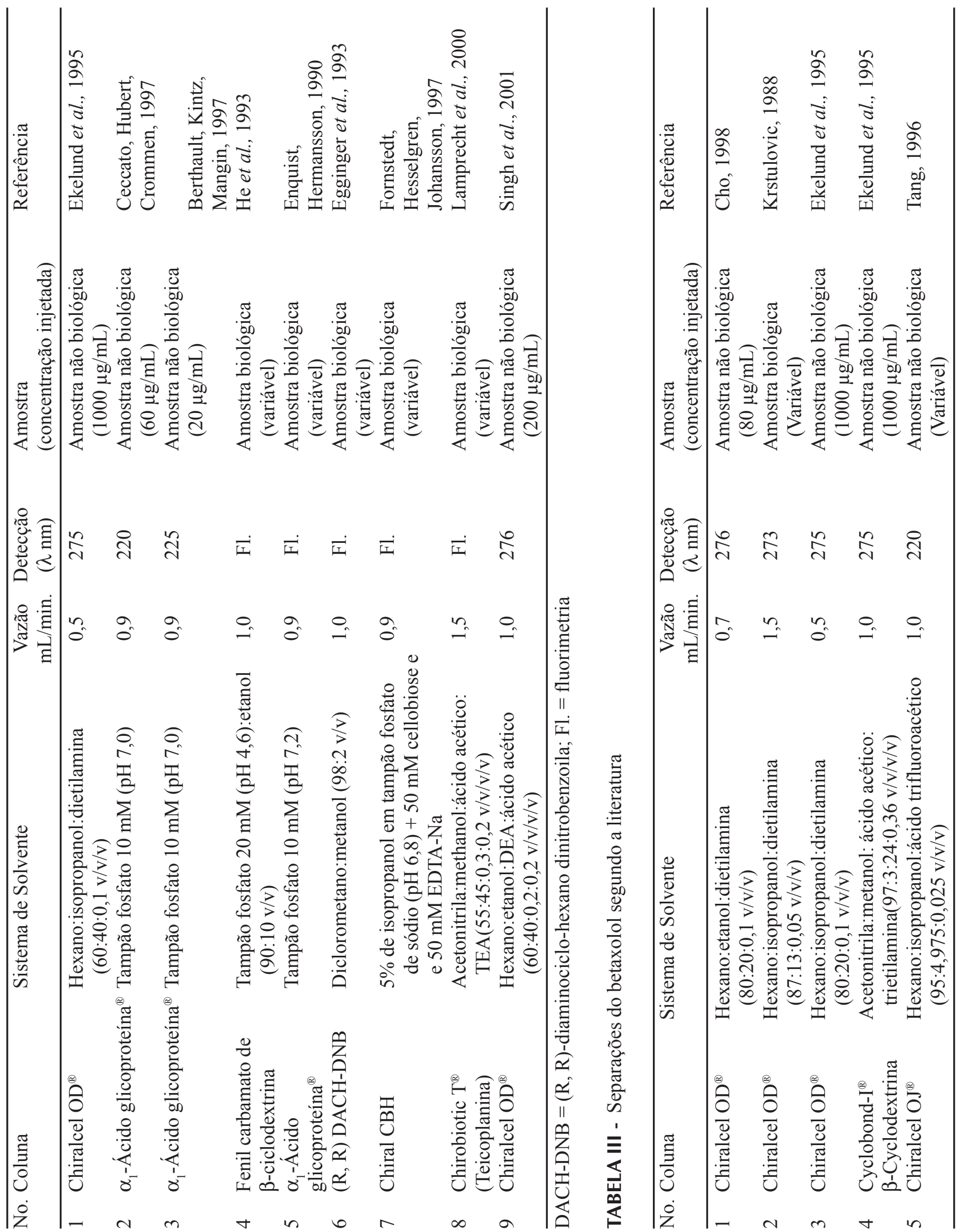


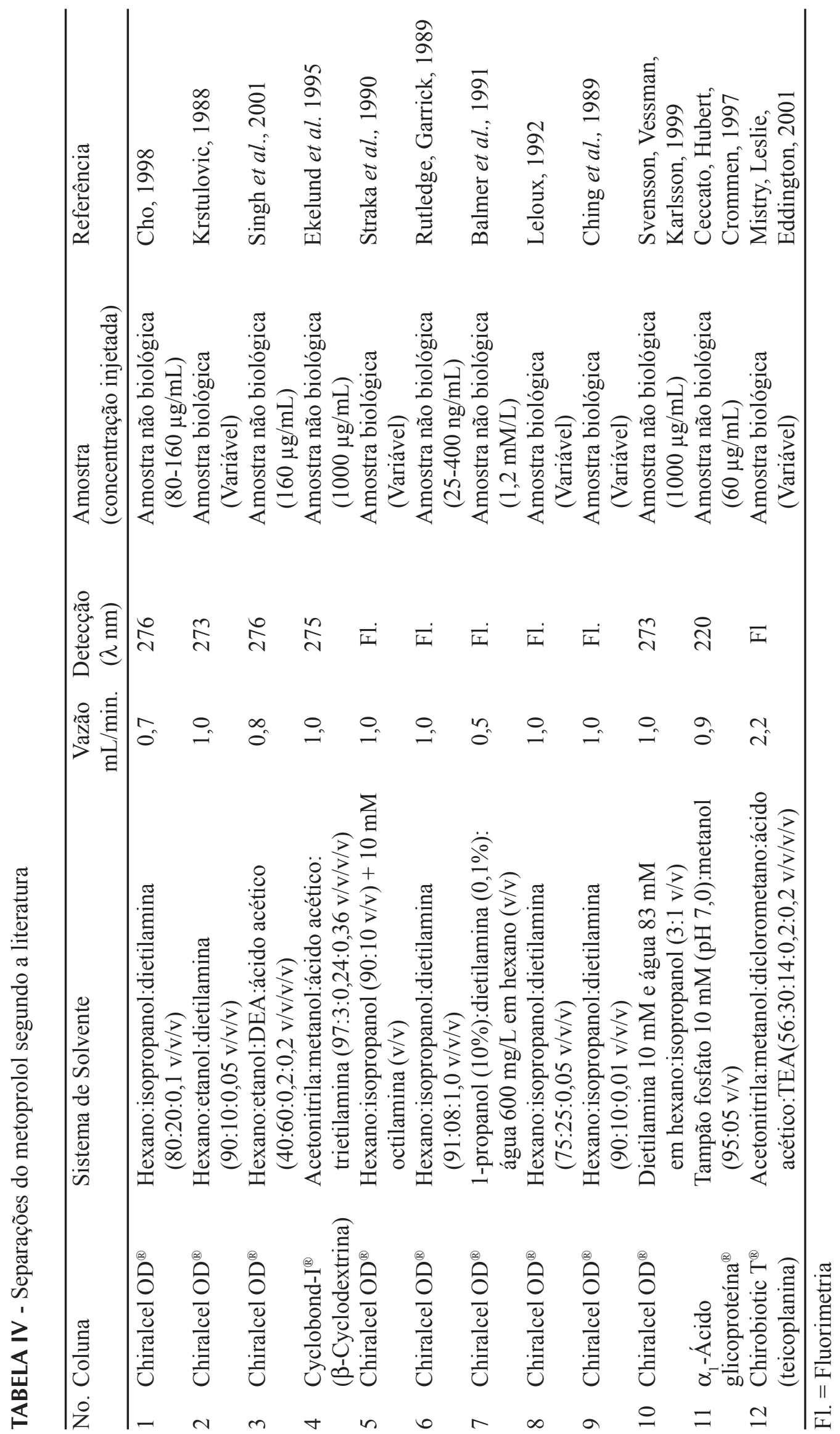




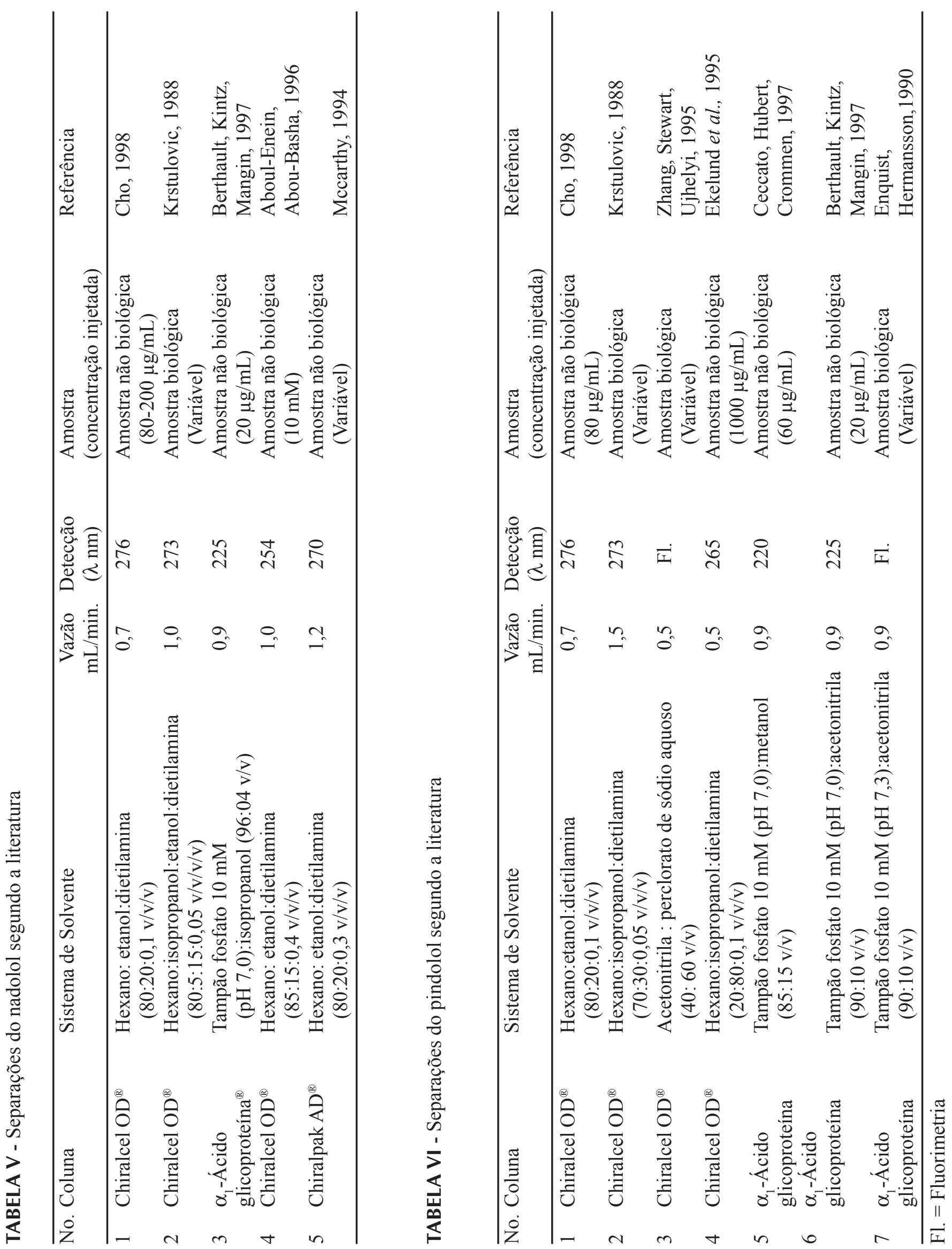


ram cromatografadas à temperatura ambiente, com volume de injeção de $20 \mu \mathrm{L}$ e vazão variando entre 0,5 e $1,0 \mathrm{~mL} / \mathrm{min}$. Normalmente, a detecção foi feita em $276 \mathrm{~nm}$. Outros comprimentos de onda foram empregados para melhorar a detecção e diminuir a absorção dos picos dos solventes. Outras variações das condições de análise serão apresentadas mais adiante.

\section{Preparação das soluções padrão}

Foram pesados exatamente 50,00 $\mathrm{mg}$ do atenolol, pindolol, nadolol, metoprolol e betaxolol separadamente e transferidos para cinco balões volumétricos de $50 \mathrm{~mL}$. Foram adicionados $40 \mathrm{~mL}$ de etanol absoluto e a solução agitada em ultra-som por $10 \mathrm{~min}$. Os volumes foram completados com etanol absoluto, obtendo-se soluções contendo $1000 \mu \mathrm{g}$ de fármaco $/ \mathrm{mL}$. A partir destas soluções, diluições foram efetuadas transferindo-se alíquotas para balões volumétricos e completando-se os volumes com a respectiva fase móvel. As soluções iniciais foram armazenadas a $-18{ }^{\circ} \mathrm{C}$ e protegidas da luz, por não mais de dois meses.

\section{Preparação das fases móveis}

As fases móveis para a coluna Chiralcel OD ${ }^{\circledR}$ foram constituídas por misturas de hexano, etanol, 2-propanol, dietilamina e/ou ácido acético. Após a preparação, as fases móveis foram filtradas através de membrana hidrofóbica, 0,45 $\mu \mathrm{m}$, Millipore ${ }^{\circledR}$ GVHP e desgaseificadas em ultra-som por $20 \mathrm{~min}$ antes do uso.

As fases móveis para a coluna $\alpha$-Burke $2^{\circledR}$ foram constituídas por misturas de acetonitrila, hexano, isopropanol, etanol, metanol e acetato de amônio. Após a preparação, as fases móveis foram filtradas através de membrana de filtro hidrofílico Durapore ${ }^{\circledR}$ PVDF 0,45 $\mu \mathrm{m}$ de tamanho de poro, diâmetro de $47 \mathrm{~mm}$ (Millipore Corporation, MA, USA) e desgaseificadas em ultra-som por 20 min antes de serem usadas.

O sistema cromatográfico foi lavado durante $60 \mathrm{~min}$ com a fase móvel antes de se dar início às injeções a fim de se equilibrar a coluna quiral e se estabilizar o sistema.

\section{RESULTADOS E DISCUSSÃO}

A importância dos fármacos do grupo dos $\beta$ bloqueadores na terapêutica cardiovascular está refletida, nos últimos cinco anos, pelo acréscimo no mercado mundial das formas enantioméricas isoladas em diversos tipos de formulações farmacêuticas (Stinson 2001). O mercado dos fármacos cardiovasculares na forma de enantiômero isolado subiu de 24,8 bilhões de dólares americanos em 1999, para 26,9 bilhões de dólares no ano 2000 (Stinson, 2001).

Alguns trabalhos de pesquisa foram publicados para separação e/ou determinação enantiomérica do atenolol, do betaxolol, do metoprolol, do nadolol e do pindolol empregando CLAE-FEQ (Tabelas II - VI). Como pode ser observado na maioria dos trabalhos descritos na literatura, a separação e a determinação quantitativa dos enantiômeros destes fármacos foi realizada em amostras biológicas, envolvendo etapas vagarosas de extração. Alem disto, os tempos de retenção altos e a baixa precisão analítica destes métodos torna-os inadequados para a analise de rotina em laboratórios de controle de qualidade de medicamentos.

Neste trabalho foram utilizadas colunas do tipo Chiralcel OD ${ }^{\circledR}$ e $\alpha$-Burke $2^{\circledR}$ visando a padronização de metodologia simples e direta para separação dos enantiômeros de $\beta$-bloqueadores, em formulações farmacêuticas comercializadas no Brasil.

Os testes de adequação do sistema são partes integrantes do método de análise por cromatografia líquida. A seletividade e o tempo de eluição dos enantiômeros são fatores importantes no desenvolvimento de métodos rápidos e eficientes. Com esta finalidade várias condições de análise foram testadas visando a obtenção de um sistema de análise otimizado.

A coluna do tipo Chiralcel OD ${ }^{\circledR}$ é derivada de carbamato de celulose tris-3,5-dimetilfenil. Para a separação enantiomérica dos $\beta$-bloqueadores, a ligação entre o hidrogênio do grupo - $\mathrm{OH}$ da parte aminoálcool do composto e o grupo carbonila do derivado de fenilcarbamato parecem ser essenciais para o reconhecimento quiral (Yashima, 2001; Yashima, Yamamoto, Okamoto, 1996). As interações entre as duplas ligações e a inclusão parcial dos enantiômeros na fase estacionária quiral também são fatores importantes (Figure 2). Estes conceitos foram levados em consideração para planejamento da parte experimental do presente trabalho de pesquisa.

A fase estacionária quiral $\alpha$-BURKE $2^{\circledR}$ é derivada de fosfonato de dimetil $N$-3,5-dinitrobenzoil- $\alpha$-amino-2, 2-dimetil-4-pentenil ligada a partículas de sílica $(5 \mu \mathrm{m})$ por ligações covalentes. A estrutura da fase estacionária quiral (S, S) a-BURKE $2^{\circledR}$ está apresentada na Figura 3. A referida fase estacionária é do tipo $\pi$-aceptor especialmente desenvolvida para a separação enantiomérica de álcoois amínicos, como os $\beta$-bloqueadores. A separação enantiomérica com esta coluna pode ser realizada em fase normal, empregando-se propanol-hexano como fase móvel, ou em fase reversa, com metanol-água. 


\section{Separação dos enantiômeros do atenolol, do betaxolol e do metoprolol}

A coluna Chiralcel OD ${ }^{\circledR}$ foi a escolhida pois propicia a separação enantiomérica de vários $\beta$-bloqueadores. Por ser uma coluna de fase normal, os solventes normalmente empregados são solventes apolares. O hexano tem sido o solvente mais utilizado e recomendado (Chiral Technologies, 2004; Singh, Kedor-Hackmann, Santoro, 2001), juntamente com o etanol e o isopropanol, empregados como modificadores orgânicos.

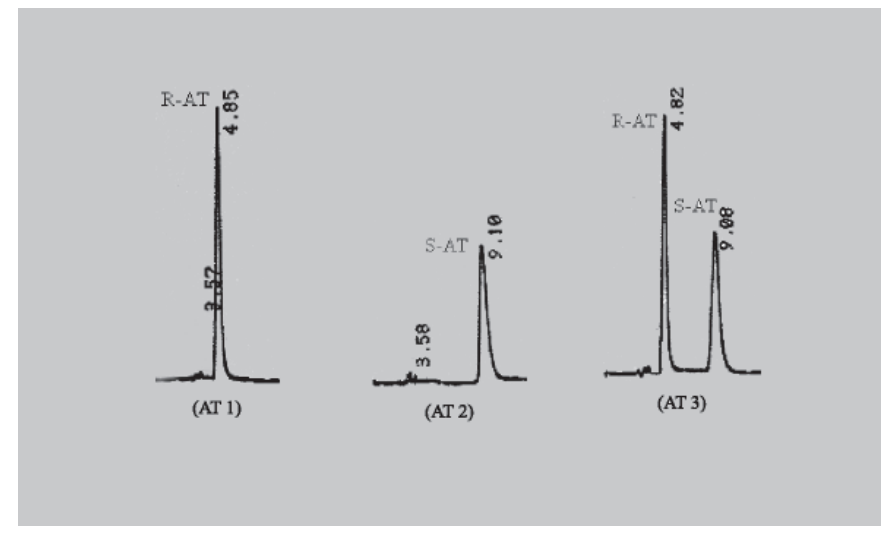

FIGURA 4 - Cromatogramas do atenolol. Condições: FEQ: Chiralcel $\mathrm{OD}^{\circledR}$; fase móvel: hexano:etanol: dietilamina:ácido acético $(60: 40: 0,2: 0,2 \mathrm{v} / \mathrm{v} / \mathrm{v} / \mathrm{v})$; vazão: $1,0 \mathrm{~mL} / \mathrm{min}$; detecção: UV $276 \mathrm{~nm}$; temperatura: ambiente $\left(24{ }^{\circ} \mathrm{C} \pm 2\right)$, Tabela I.

Com base nos resultados preliminares observou-se que a dietilamina diminui a cauda e melhora a resolução dos picos. Os resultados confirmaram que 0,1 ou $0,2 \%$ de dietilamina são as quantidades apropriadas para diminuir a cauda sem danificar a coluna, pois a dietilamina é extremamente básica, sendo por este motivo utilizada somente em pequenas quantidades. Além disso, em alguns casos, esta substância diminui o tempo de retenção e melhora o perfil do pico (Okamoto, Kaida, 1994; Tang, 1996). Devido ao caráter básico dos $\beta$-bloqueadores, a dietilamina foi escolhida como modificador orgânico. A dietilamina aumenta o $\mathrm{pH}$ (aparente) da fase móvel para intervalos de 9 a 11 e evita interações secundárias entre fármacos básicos, tipo $\beta$ bloqueadores, e os sítios dos silanóis da fase estacionária quiral e ainda converte o grupo básico em uma das suas formas neutras. Assim, o tempo de retenção é reduzido e a cauda minimizada (Tang, 1996).

Foram realizados testes empregando-se hexano, isopropanol, etanol e metanol em diferentes proporções, com e sem adição de dietilamina e/ou ácido acético. Aumentando-se a polaridade da fase móvel, seja pelo aumento da proporção de álcool ou por alteração do tipo de álco-

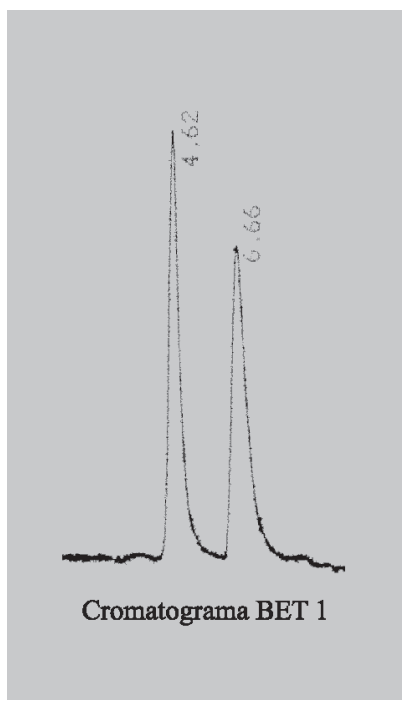

FIGURA 5 - Cromatograma do betaxolol. Condições: FEQ: Chiralcel $\mathrm{OD}^{\circledR}$; fase móvel: hexano:isopropanol: dietilamina (70:30:0,1 v/v/v); vazão: $1,0 \mathrm{~mL} / \mathrm{min}$; detecção: UV $276 \mathrm{~nm}$; temperatura: ambiente $\left(24^{\circ} \mathrm{C} \pm 2\right)$, Tabela I.

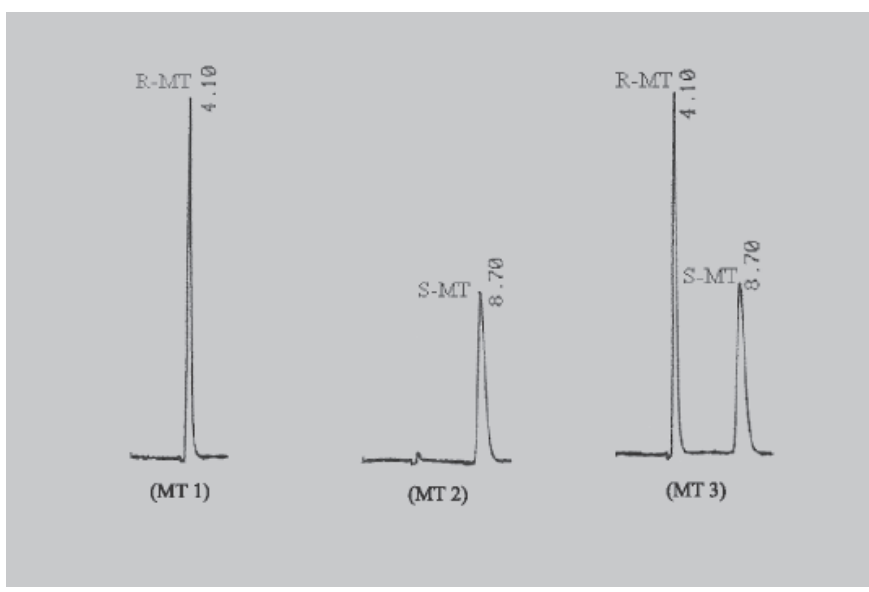

FIGURA 6 - Cromatogramas do metoprolol. Condições: FEQ: Chiralcel $\mathrm{OD}^{\circledR}$; fase móvel: hexano:etanol: dietilamina:ácido acético (40:60:0,2:0,2 v/v/v/v); vazão: $0,8 \mathrm{~mL} / \mathrm{min}$; detecção: UV $276 \mathrm{~nm}$; temperatura: ambiente $\left(24^{\circ} \mathrm{C} \pm 2\right)$, Tabela I.

ol (isopropanol ou etanol), observou-se diminuição do tempo de retenção. O álcool na fase móvel pode competir com os fármacos pela fase estacionária devido à formação de ligações hidrogênio. O isopropanol, por ser um álcool de massa molecular maior do que a do etanol, teria limitações estéricas maiores, apresentando menor competição com os analitos para a fase estacionária (Kirkland, 1995). Os álcoois de alta massa molecular apresentam tendência reduzida para interagir por ligações hidrogênio com a fase estacionária de celulose modificada, promovendo alta resolução enantiomérica para compostos que 
também competem com estes sítios potencialmente ativos.

No entanto, a escolha do álcool é caracterizada pelo tipo e tempo de análise, que deve ser preferencialmente curto. Os ensaios preliminares com etanol e isopropanol indicaram resultados favoráveis ao etanol. A presença de base orgânica e de ácido orgânico, em pequenas quantidades, na fase móvel apresentou efeito vantajoso sobre a separação enantiomérica.

De modo geral, observou-se que houve melhora na separação enantiomérica de fármacos com caráter básico, como no caso de $\beta$-bloqueadores, na presença de ácido acético. A adição de ácido aumenta a resolução (Rs) pela formação de picos agudos. Entretanto, os picos apresentaram, também, seletividade suficiente para separar os enantiômeros de $\beta$-bloqueadores, mesmo na ausência de ácido orgânico. Os ácidos orgânicos, quando presentes na fase móvel, favorecem a formação de pares iônicos com os analitos básicos dos $\beta$-bloqueadores (Tang, 1996).

As vazões empregadas em todos os métodos propostos para a separação dos enantiômeros foram estudadas durante a otimização de cada método. Tomou-se como fator limitante a pressão máxima que a coluna Chiralcel $\mathrm{OD}^{\circledR}$ suporta sem se danificar, o que implicou a impossibilidade do emprego de vazão maior do que $1,0 \mathrm{~mL} / \mathrm{min}$.

\section{Separação dos enantiômeros do nadolol}

O nadolol, apesar de possuir três carbonos quirais, apresenta apenas dois centros quirais, pois as hidroxilas do carbono 2-3 são fixas na configuração cis, permitindo um total de quatro estereoisômeros. Os estereoisômeros do nadolol foram separados empregando-se a coluna Chiralcel OD ${ }^{\circledR}$ e detecção no UV em 276 nm.

Verificou-se na literatura que os dois primeiros picos são os isômeros (RSR)-nadolol e (RRS)-nadolol que são as formas dextrógiras $(+)$ (Aboul-Enein et al. 1996). O terceiro pico seria o (SRS)-nadolol que também é dextrógiro. O quarto, corresponderia ao (SSR)-nadolol que é levógiro (-) quando se emprega coluna do tipo Chiralcel $\mathrm{OD}^{\circledR}$. Esta seqüência de eluição foi obtida por Aboul-Enein e colaboradores (1996) usando detector óptico Shodex OS-1, com o qual é possível identificar as rotações ópticas dos enantiômeros. Os autores verificaram que não ocorrem alterações na ordem de eluição quando se empregam fases móveis de mesma constituição. No entanto, os autores do referido trabalho não apresentaram separação pela injeção simultânea dos quatro enantiômeros na forma racêmica. Resultados semelhantes foram obtidos por McCarthy (Mccarthy, 1994), utilizando coluna do tipo Chiralpak $\mathrm{AD}^{\circledR}$ e fase móvel contendo hexano:etanol:dietilamina (80:20:0,3 v/v/v) com vazão de
$1,2 \mathrm{~mL} / \mathrm{min}$. Neste caso, também o isômero R, R,S foi o primeiro a eluir e o isômero R,S,S, o último. Os autores deste trabalho obtiveram separação enantiomérica pela injeção simultânea dos quatro isômeros na forma racêmica.

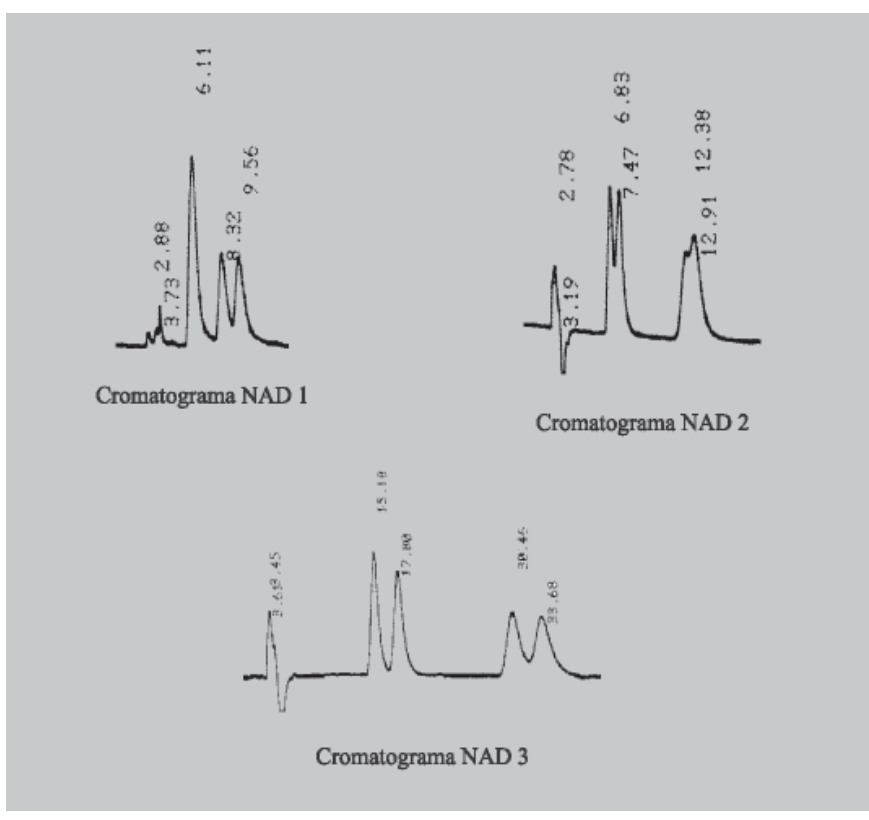

FIGURA 7 - Cromatogramas do nadolol. Condições: FEQ: Chiralcel OD ${ }^{\circledR}$; NAD 1 - fase móvel: hexano:etanol: dietilamina (80:20:0,1 v/v/v) com vazão de $1,0 \mathrm{~mL} / \mathrm{min}$; NAD 2 - fase móvel: hexano:etanol:dietilamina:ácido acético (80:20:0,2:0,2 v/v/v/v) com vazão de $1,0 \mathrm{~mL} / \mathrm{min}$; NAD 3 - fase móvel: hexano:etanol:dietilamina:ácido acético (87:15:0,2:0,2 v/v/v/v) com vazão de $0,8 \mathrm{~mL} / \mathrm{min}$; detecção: UV $276 \mathrm{~nm}$; temperatura: ambiente $\left(24^{\circ} \mathrm{C} \pm 2\right)$.

Foram realizados testes empregando-se sistema constituído por hexano, etanol, isopropanol, com dietilamina e ácido acético. Em todos os casos houve separação parcial entre os picos. Após várias tentativas, foi possível a separação completa dos quatro estereoisômeros do nadolol, utilizando-se hexano:etanol:dietilamina:ácido acético (87:13:0,2:0,2 v/v/v/v) com vazão de $0,8 \mathrm{~mL} / \mathrm{min}$. A detecção foi efetuada a $276 \mathrm{~nm}$. Os quatro picos do nadolol apresentaram a seletividade desejada e eluiram com os seguintes tempos de retenção: 15,18; 17,80; 30,46 e 33,68 min, respectivamente (Tabela I).

\section{Separação dos enantiômeros do pindolol}

Vários métodos indiretos foram publicados sobre a separação enantiomérica do pindolol empregando a préderivatização dos enantiômeros ou utilizando FEQs. O problema principal com a separação enantiomérica deste 
composto é o tempo de análise, especialmente, o tempo de retenção do enantiômero (S)-pindolol. Até mesmo no sistema sugerido pelos fabricantes da coluna Chiralcel OD ${ }^{\circledR}$, o tempo de retenção para a eluição dos enantiômeros é de 50 min (Chiral Technologies, 2004).

Com base nos dados fornecidos pelo próprio fabricante da coluna concluiu-se que o (R)-pindolol foi eluído antes do (S)-pindolol, quando se utiliza coluna Chiralcel $\mathrm{OD}^{\circledR}$ com sistema de fase móvel em modo normal. As formas dos picos foram sensivelmente melhoradas quando se adicionou $0,1 \%$ de dietilamina na fase móvel.

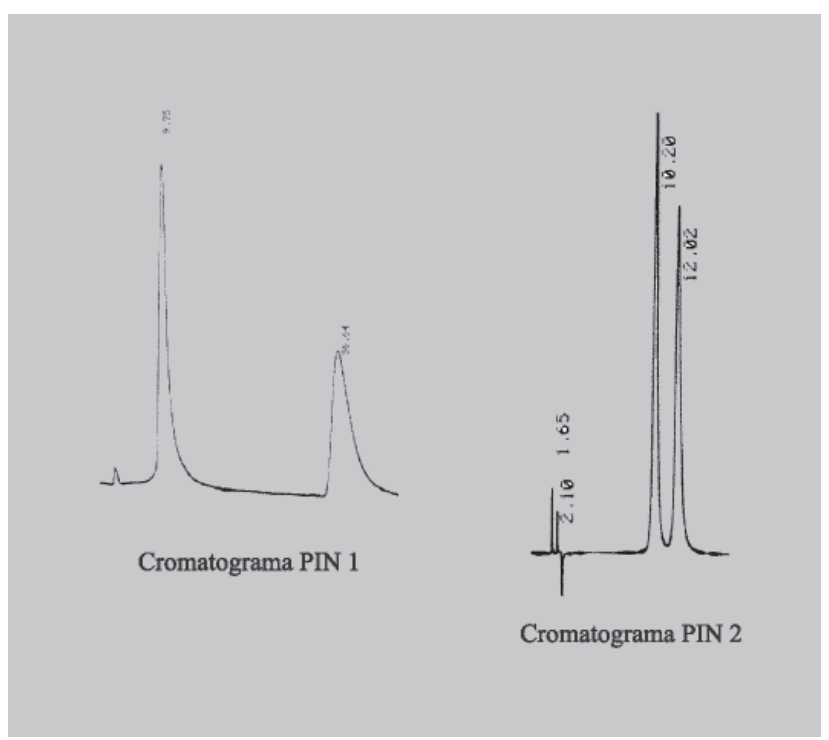

FIGURA 8 - Cromatogramas do pindolol. Condições PIN 1: FEQ: Chiralcel $\mathrm{OD}^{\circledR}$; fase móvel: hexano:etanol: dietilamina (80:20:0,1 v/v/v); vazão: $1,0 \mathrm{~mL} / \mathrm{min}$; detecção: UV 254 nm; Condições PIN 2: FEQ: $\alpha$-Burke $2^{\circledR}$; fase móvel: acetonitrila:etanol $(50: 50 \mathrm{v} / \mathrm{v}) \operatorname{com} 21,62 \mathrm{mM}$ de acetato de amônia; vazão: 1,3 $\mathrm{mL} / \mathrm{min}$; detecção: UV 220 $\mathrm{nm}$; temperatura: ambiente $\left(24^{\circ} \mathrm{C} \pm 2\right)$.

O sistema constituído por hexano:etanol:dietilamina (80:20:0,1 v/v/v), com vazão de $1,0 \mathrm{~mL} / \mathrm{min}$ e detecção em $254 \mathrm{~nm}$, deu origem a separação com excelente seletividade e resolução (Figura 8). O pico mais retido, o (S)-pindolol, foi eluído em 36,64 min, apresentando boa simetria. O tempo de retenção mostrou a inviabilidade do emprego em análise enantiomérica de rotina (Tabela I).

O comprimento de onda empregado na análise possui grande efeito sobre o formato e simetria dos picos. Por esta razão, é importante escolhê-lo cuidadosamente. A detecção, realizada em $276 \mathrm{~nm}$, aumentou a interferência da fase móvel e a instabilidade da linha de base.

Ensaios foram realizados para separação enantiomérica do pindolol em FEQ do tipo $\alpha$-Burke $2^{\circledR} \mathrm{e}$ acetonitrila como eluente, ao invés de diclorometano.
Observou-se, também, que um acréscimo na polaridade da fase móvel, em virtude do aumento da concentração do modificador polar, etanol por exemplo, promove diminuição no tempo de retenção. Após vários estudos preliminares, foram estabelecidas as condições ideais para separação dos enantiômeros do pindolol com tempo de análise mais curto (12 min). A fase móvel foi constituída por acetonitrila:etanol $(50: 50 \mathrm{v} / \mathrm{v})$, acrescida de acetato de amônio 21,62 mM, à vazão de 1,3 $\mathrm{mL} / \mathrm{min}$ e detecção em $220 \mathrm{~nm}$. O enantiômero (R)-pindolol foi eluído primeiro, seguido do (S)-pindolol, confirmando o fato de que o enantiômero (S) apresenta ligações mais fortes com a FEQ do tipo (S,S) $\alpha$-Burke $2^{\circledR}$ (Tabela I).

Para diminuir a basicidade da molécula do pindolol seria necessária uma derivatização transitória do grupo amino da molécula. $\mathrm{O}$ acetato de amônio, no entanto, age promovendo protonização reversível da molécula, possibilitando a ligação necessária para o reconhecimento quiral. Foi observado que a presença de íons de amônio era essencial para ocorrer a separação e para eluição dos picos.

\section{Efeito da temperatura sobre a separação dos enantiô- meros do pindolol}

O efeito da temperatura na separação enantiomérica do pindolol empregando colunas do tipo $\alpha$-Burke $2^{\circledR}$ foi também estudado. Observou-se que o $\mathrm{k}_{1}$ e o $\mathrm{k}_{2}$ aumentam com acréscimo da temperatura da coluna $\left(5\right.$ a $\left.55^{\circ} \mathrm{C}\right)$, sem considerável alargamento dos picos. Por outro lado, houve pequena melhora na seletividade dos picos quando comparada com as separações obtidas em temperatura ambiente.

\section{CONCLUSÕES}

Todos os enantiômeros dos fármacos estudados neste trabalho foram separados em tempo curto de análise. Um sistema inédito de CLAE-FEQ foi desenvolvido para separar os quatro estereoisômeros do nadolol em única injeção. Neste sistema foram separados os estereoisômeros: (R,S,R, RRS, SRS, SSR)-nadolol, entretanto, não foi possível a determinação da ordem de eluição devido à inexistência de padrões dos enantiômeros puros. A separação enantiomérica do pindolol foi possível empregando-se FEQ Chiralcel OD ${ }^{\circledR}$, entretanto, o tempo de análise prolongado impossibilita o emprego na análise rotineira dos enantiômeros do pindolol. A mesma separação foi possível em tempo mais curto e com eficiência através da CLAE-FEQ, empregando a coluna $\alpha$ Burke $2^{\circledR}$, com fase móvel orgânica. A vantagem principal dos métodos propostos, após a necessária validação, é a possibilidade de aplicação na separação dos enantiômeros dos fármacos estudados de maneira adequada, eficiente e rápida. 


\section{ABSTRACT}

\section{Applied chiral phase liquid chromatography in} enantiomeric separation of cardiovascular drugs

The majority of frequently prescribed therapeutic agents are formulated and commercialized in the racemic form, even though, for some of them, it has already been demonstrated that the pharmacological and/or toxicological effects are associated only with one of the enantiomers. Moreover, it is well known that these antipodes can present different pharmacokinetic and pharmacodynamic profiles. In this work we selected drugs that belong to an important group of pharmaceuticals, frequently prescribed in the treatment of cardiovascular disorders. The direct enantiomeric separations of atenolol, betaxolol, metoprolol and nadolol were obtained using the chiral stationary phase cellulose tris3,5-dimethylphenyl-carbamate, Chiralcel $O D^{\circledR}(250 x$ 4,6 mm, $10 \mu \mathrm{m})$. The enantiomers of pindolol were separated with the chiral stationary phase derived from dinitro-benzoyl (DNB) $(S, S) \alpha$-Burke $2^{\circledR}(250 \times 4.6 \mathrm{~mm}, 10 \mu \mathrm{m})$. The drugs were chromatographed at room temperature, with injection volumes of $20 \mu \mathrm{L}$. The detention was made at $276 \mathrm{~nm}$ except for pindolol, which was detected at $220 \mathrm{~nm}$. The proposed methods in this work using HPLC-CSP offer advantages over contemporaneous techniques of enantiomeric separation, being rapid and efficient, and can be used in the simultaneous quantitative analysis of referred enantiomers in pharmaceutical preparations and biological samples.

UNITERMS: Liquid chromatography. Chiral stationary phase. Enantiomeric separation. $\beta$-blockers.

\section{AGRADECIMENTOS}

Os autores agradecem à "Fundação de Amparo à Pesquisa do Estado de São Paulo (FAPESP)", São Paulo, SP, Brasil, pelo suporte financeiro.

\section{REFERÊNCIAS BIBLIOGRÁFICAS}

ABOUL-ENEIN, H.Y. Application of cellulose based chiral stationary phases in the resolution of some betaadrenoceptor antagonists. Anal. Lett., New York, v.26, p.271-279, 1993 .

ABOUL-ENEIN, H.Y.; ABOU-BASHA, L.I.HPLC separation of nadolol and enantiomers on chiralcel OD column.J. Liq. Chromatogr., New York, v.19, p.383-392, 1996.
AHUJA, S. Chiral separation by liquid chromatography. Washington: American Chemical Society, 1991.239p.

BELAS, F.J.; PHILLIPS, M.A.; SRINIVAS, N.R.; BARBHAIYA, R.H.; BLAIR, I.A. Simultaneous determination of nadolol enantiomers in human plasma by high-performance liquid chromatography using fluorescence detection. Biomed. Chromatogr., Bognor Regis, v.9, n.3, p.140-145, 1995.

BALMER, K.; PERSSON, A.; LAGERSTROM, P.; PERSSON, B.; SCHILL, G. Liquid-chromatographic separation of the enantiomers of metoprolol and its alphahydroxy metabolite in Chiralcel OD for determination in plasma and urine. J. Chromatogr., Amsterdam, v.553, p.391-397, 1991.

BERTHAULT, F.; KINTZ, P.; MANGIN, P. Chiral separation of seven beta-blockers. Ann. Pharm. Fr., Paris, v.55, p.12-19, 1997.

CECCATO, A.; HUBERT, P.; CROMMEN, J. Direct liquidchromatographic enantioseparation of sotalol and other beta-blockers using an alpha1-acid glycoprotein-based chiral stationary phase. J. Chromatogr., Amsterdam, v.760, p.193-203, 1997.

CHING, M.S.; LENNARD, M.S.; GREGORY, A.; TUCKER, GT. Measurement of underivatized metoprolol enantiomers in human plasma by high performance liquid chromatography with a chiral stationary phase. $J$. Chromatogr., B: Biomed. Sci. Appl., Amsterdam, v.497, p.313-318, 1989.

CHIRAL Application Guide-V, Morton Grove: Regis Technologies, 2004. 89 p.

CHIRAL TECHNOLOGIES. Technical support, products and services for chiral analysis and separation. Daicel Chemical Industries: Japan. Disponível em: $<$ http:// www.daicel.co.jp>. Acesso em: 24 set. 2004.

CHO, H.S. Determinação enantiomérica de $\beta$-bloqueadores em medicamentos por cromatografia liquida de alta eficiência com fase quiral. São Paulo, 1998. p.177. [Tese de Doutorado. Faculdade de Ciências Farmacêuticas. Universidade de São Paulo].

DAPPEN, R.; ARM, H.; MAYER, V.R. Applications and limitations of commercially available chiral stationary phases for high performance liquid chromatography. $J$. Chromatogr., Amsterdam, v.373, p.1-20, 1986. 
DARMON, A.; THENOT, J.P. Determination of betaxolol enantiomers by high-performance liquid chromatography: application to pharmacokinetic studies. J. Chromatogr., Amsterdam, v.374, p.321-328, 1986.

DEF 2003/2004 Dicionário de especialidades farmacêuticas. 29.ed. Rio de Janeiro: Publicações Cientificas, 2003. 1186p.

EGGINGER, G.; LINDNER, W.; VANDENBOSCH, C.; MASSART, D. Enantioselective bioanalysis of $\beta$ blocking agents: focus on atenolol, betaxolol, carvedilol, metoprolol, pindolol, propranolol and sotalol. Biomed. Chromatogr., London, v.7, p.277-295, 1993.

EGGINGER， G.; LINDNER，W.; KAHR， S.; STOSCHITZKY, K. Sterioselective HPLC bioanalysis of atenolol enantiomers in plasma: application to a comparative human pharmacokinetic study. Chirality, New York, v.5, p.505-512, 1993.

EKELUND, J.; ARKENS, A.V.; BRONNUM-HANSEN, K.; FICH, K.; OLSEN, L.; PETERSON, P.V. Chiral separations of $\beta$-blocking drug substances using chiral stationary phases. J. Chromatogr., A, Amsterdam, v.708, p.253-261, 1995.

ENQUIST, M.; HERMANSSON, J. Separation of the enantiomers of beta-receptor blocking agents and other cationic drugs using a CHIRAL-AGP column. Binding properties and characterization of immobilized acid glycoprotein. J. Chromatogr., Amsterdam, v.519, p.285298, 1990.

FORNSTEDT, T.; HESSELGREN, A.M.; JOHANSSON, M. Chiral assay of atenolol present in macrodialysis and plasma samples of rats using chiral $\mathrm{CBH}$ as stationary phase. Chirality, New York, v.9, p.329-334, 1997.

HE, J.; SHIBUKAWA, A.; NAKAGAWA, T.; WADA, H.; FUJIMA, H.; IMAI, E.; GO-OH, Y. Direct injection analysis of atenolol enantiomers in plasma using an achiral-chiral coupled column HPLC system. Chem. Pharm. Bull., Tokyo. v.41, p.544-548, 1993.

HERMANSSON, J.; VON BAHR, C. Determination of(R)and (S)-alprenolol and (R)- and (S)-metoprolol as their diastereomeric derivatives in human plasma by reversedphase liquid chromatography. J. Chromatogr., Amsterdam, v.227, p.113-127, 1982.
HERRING, V.L.; BASTIAN, T.L.; LALONDE, R.L. Solid phase extraction and direct high performance liquid chromatographic determination of metoprolol enantiomers in plasma. J. Chromatogr., Amsterdam, v.567, p.221-227, 1991

FOYE, W.O., ed. Principles of medicinal chemistry. 3.ed. Philadelphia: Lea \& Febiger, 1989. p.51-52.

HOFFMAN, B.B.; LEFKOWITZ, R.J. In: HARDMAN, J.G.; MOLINOFF, P.B.; RUDDON, R.W.; GILMAN, A.G., (Eds.). Goodman \& Gilman's the pharmacological basis of therapeutics. 9.ed. New York: McGraw-Hill, 1996. $1905 \mathrm{p}$

KIRKLAND, K.M. Optimization of chiral selectivity on cellulose based high-performance liquid chromatographic columns using aprotic mobile phase modifiers. $J$. Chromatogr., Amsterdam, v.718, p.9-26, 1995.

KRSTULOVIC, A.M.; FOUCHET, M.H.; BURKE, J.T.; GILLET, G.; DURAND, A. Direct enantiomeric separation of betaxolol with applications to analysis of bulk drug and biological samples. J. Chromatogr., Amsterdam, v.452, p.477-483, 1988.

LAMPRECHT, G.; KRAUSHOFER, T.; STOSCHITZKY, K.; LINDNER, W. Enantioselective analysis of (R)- and (S)-atenolol in urine samples by a high-performance liquid chromatography column-switching setup. $J$. Chromatogr., B: Biomed. Sci. Appl., Amsterdam, v.740, p.219-226, 2000.

LELOUX, M.S. Rapid chiral separation of metoprolol in plasma: application to the pharmacokinetics/pharmacodynamics of metoprolol enantiomers in the conscious goat. Biomed. Chromatogr., London, v.6, p.99-105, 1992.

McCARTHY, J.P. Direct enantiomeric separation of the four stereoisomers of nadolol using normal-phase and reversed-phase high-performance liquid chromatography with Chiralpak AD. J. Chromatogr., Amsterdam, v.685, p.349-355, 1994.

MEHVAR, R.; BROCKS, D.R. Steriospecific pharmacokinetics and pharmacodynamics of beta-adrenargic blockers in humans. J. Pharm. Sci., Washington, v.4, p.185-200, 2001. 
MISTRY,B.; LESLIE, J.L.; EDDINGTON, N.D. Enantiomeric separation of metoprolol and alpha hydroxymetoprolol by liquid chromatography and fluorescence detection using a chiral stationary phase. J. Chromatogr., B: Biomed. Sci. Appl., Amsterdam, v.758, p.153-161, 2001.

MOFFAT, A.C.; JACKSON, J.V.; MOSS, M.S.; WIDDOP, B. In:__. Clarke's isolation and identification of drugs in pharmaceuticals, body fluids and post-mortem material. 2.ed. London: Pharmaceutical Press, 1986. 1223 p.

OKAMOTO, Y.; KAIDA, Y. Resolution by high performance liquid chromatography using polysaccharide carbamates and benzoates as chiral stationary phases. J. Chromatogr., Amsterdam, v.666, p.403-419, 1994.

PIRKLE, W.H.; BURKE, J.A. Chiral stationary phase designed for beta-blockers. J. Chromatogr., Amsterdam, v.557, p.173-185, 1991.

RUTLEDGE, D.R.; GARRICK, C. Rapid high-performance liquid-chromatographic method for the measurement of the enantiomers of metoprolol in serum using a chiral stationary phase. J. Chromatogr., B: Biomed. Sci. Appl., Amsterdam, v.497, p.181-190, 1989.

SANTORO, M. I. R. M.; SINGH, A. K. Development and regulation of chiral drug substances: an overview on worldwide pharmaceutical guidelines. Rev. Bras. Cienc. Farm., São Paulo, v. 37, n. 3, p. 259-268, 2001.

SINGH, A. K.; KEDOR-HACKMANN, E. R. M.; SANTORO, M. I. R. M.. Development and validation of chiral HPLC method for quantitative analysis of atenolol and metoprolol enantiomers in tablet preparations. J. AOAC Int., Arlington, v.84, p. 1724-1729, 2001.

SRINIVAS, N.R.; BARR, W.H.; SHYU, W.C.; MOHANDOSS, E.; CHOW, S.; STAGGERS, J.; BALAN, G.; BELAS, F.J.; BLAIR, I.A.; BARBHAIYA, R.H. Bioequivalence of two tablet formulations of nadolol using single and multiple dose data: assessment using stereospecific and nonstereospecific assays. $J$. Pharm. Sci., New York, v.85, p.299-303, 1996.

STINSON, S.C. Chiral chemistry: driven by the needs of the drug industry and fuled by the ingenuity of chemists, sales of single-enantiomer chiral compounds keep accelerating. Chem. Eng. News, Columbus, v.79, p.45-57, 2001.
STRAKA, R.J.; JOHNSON, K.A.; MARSHALL, P.S.; REMMEL, R.P. Analysis of metoprolol enantiomers in human serum by liquid chromatography on a cellulosebased chiral stationary phase. J. Chromatogr., B: Biomed. Sci. Appl., Amsterdam, v.530, p.83-93, 1990.

SVENSSON, S.; VESSMAN, J.; KARLSSON, A. Direct high performance liquid chromatographic separation of metoprolol analogues on a chiralcel OD column using chemometrics. J. Chromatogr., Amsterdam, v.839, p.2339, 1999 .

TANG, Y. Significance of mobile phase composition in enantio-separation of chiral drugs by HPLC on a cellulose based chiral stationary phase. Chirality, New York, v.8, p.136-142, 1996.

WAINER, I.W. HPLC chiral stationary phases for the steriochemical resolution of enantiomeric compounds, the current state of the art. In: Drug stereochemistry: analytical methods and pharmacology. 2.ed. New York: Dekker, 1993. p.139-182. (Clinical pharmacology, v.18).

WARD, T.J.; ARMSTRONG, D.W. Cyclodextrin stationary phases. In: ZIEF, M., CRANE, L.J. Chromatographic chiral separations. New York: Marcel Dekker, 1988. p.131-163.

YASHIMA, E. Polysaccharide-based chiral stationary phases for high performance liquid chromatographic enantioseparation. J. Chromatogr., Amsterdam, v.906, p.105-125, 2001.

YASHIMA, E.; YAMAMOTO, C.; OKAMOTO, Y. NMR studies of chiral discrimination relevant to the liquid chromatographic enantioseparation by a cellulose phenylcarbamate derivative. J. Am. Chem. Soc., Columbus, v.118, p.4036-4048, 1996.

ZHANG, H.; STEWART, J.T.; UJHELYI, M. Highperformance liquid chromatographic analysis of pindolol enantiomers in human serum and urine using a reversedphase cellulose-based chiral column. J. Chromatogr., $B$ : Biomed. Sci. Appl.,Amsterdam, v.668, p.309-313, 1995.

Recebido para publicação em 08 de abril de 2005 Aceito para publicação em 18 de agosto de 2006 